\title{
45. On the Ontogenic Development of Blood Group Substances in Fetuses and New Born Children.
}

By Tanemoto Furuhata, M.J.A. and Shiro INO.

The Institute of Legal Medicine, Medical Faculty, University of Tokyo. (Director T. FURUHATA)

(Comm. by T. FuruhatA, M. J. A., June 16, 1949.)

\section{Introduction.}

Minute studies have already been conducted on the A, B and $\mathrm{AB}$ blood types in connection with the agglutinability of fetuses' blood corpuscles with the following facts being generally recognized. The existence of blood group substances is proved even in the early embryonic period, blood group substances gradually developing till they attain their perfect growth within several years after fetuses' birth. Thereafter their agglutinability maintain a certain normalcy till they are weakend at men's old age.

On the other hand, as FISK, FOORD, UNGER, etc. point out the fact that the agglutinogen which corresponds to the anti-Rh sera obtained by injecting a rhesus monkey's blood corpuscles to a guinea pig is especially strong in a new born child we re-examined this fact with $\mathrm{Rh}$ agglutinogen and at the same time studied the development and growth of $\mathrm{Q}$ agglutinogen and partial antigens of $\mathrm{A}, \mathrm{B}$ and $\mathrm{C}$ blood group substances and $\mathrm{O}$ substance in fetuses and new born children, on the results of which we now give a report as follows :

\section{Preparation of Anti-Sera.}

Anti-Rh sera were obtained by injecting a rhesus monkey's blood corpuscles into the abdominal cavity of a guinea pig by the method of LANDSTEINER and WIENER (1941).

For anti-Q sera, the sera selected from pig's sera by M. IMA MURA'S method were employed.

Partial anti-bodies of $\mathrm{A}, \mathrm{B}$ and $\mathrm{C}$ blood group substances and $\mathrm{O}$ substance were prepared by the method of $Y$. INOUE, K. YAMAGUCHI and C. KOBAYASHI, etc.

\section{Experiment.}

For examination of $\mathrm{Rh}$ agglutinogen, small test tubes were used and examination was conducted on the decision obtained after two hours as in the experiment carried out by LANDSTEINER and WIENER. For examination of other agglutinogens, object-glass was used and decision was obtained after 30 minutes. The strength of 
agglutinability was tabulated by \% by KEMP'S method. For example, when the sera, which agglutinate the standard blood corpuscles (a specific adult's blood corpuscles) till the sera are diluted just 60 times, agglutinate a new born child's blood corpuscles till the above sera are diluted 30 times, the agglutinability of this new born child is shown as $50 \%$ in the diagram. The results of examination conducted on 200 new born children and 96 fetuses are shown in the attached diagram on the mathematical average.

\section{Results.}

The $\mathrm{Rh}$ agglutinogen which corresponds to a guinea pigs sera, as FISK and UNGER propound, most strongly develops in a new born child and becomes weakend speedily after birth. The $\mathrm{Rh}$ agglutinogen is already in a fairly well developed condition towards the end of the 2nd embryonic month, becomes stronger than that of an adult at the end of the 3rd embryonic month, speedily develops even thereafter till it attains nearly its perfection in the 7th embryonic month and becomes nearly 5 times as strong as that of an adult, and is weakened speedily after birth till it obtains its normalcy in two or three months time after birth.

Though the $Q$ agglutinogen which corresponds to anti- $Q$ sera in the normal sera of pigs shows also a similar change to that of the $\mathrm{Rh}$ agglutinogen above mentioned, its change after birth is far less than that of the $\mathrm{Rh}$ agglutinogen.

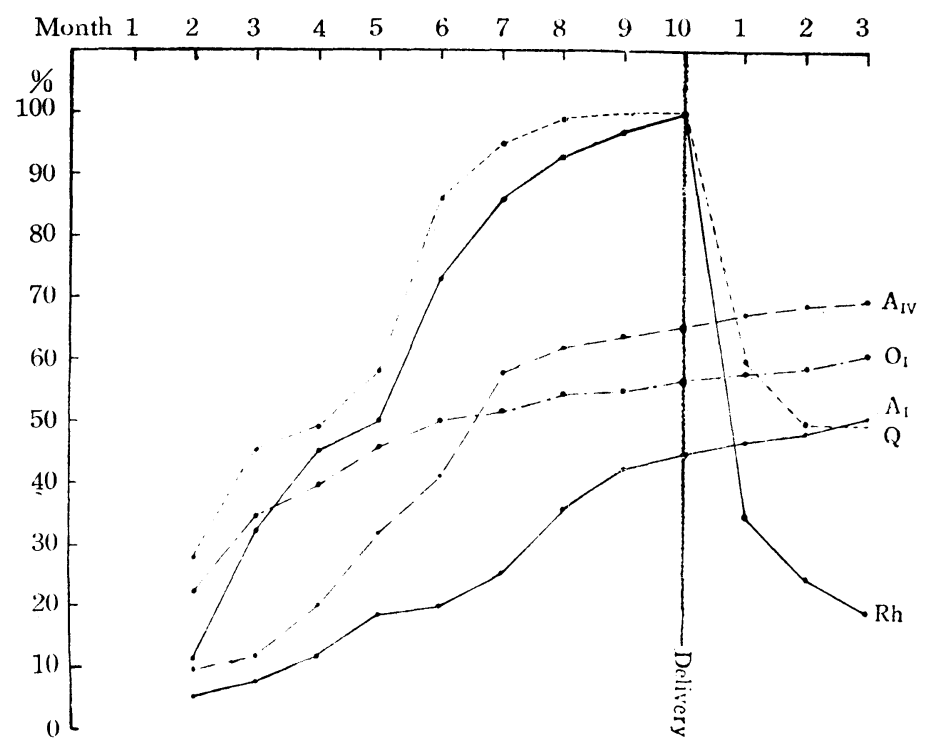

The results of the studies on the partial agglutinogens of $A$ and $B$ blood group substances $A_{1} A_{11} A_{111} A_{11}, B_{1} B_{11} B_{111}$ and $C_{1} C_{11} C_{111}$ show that the lower the degree of the partial agglutinogens is, the more 
speedily they develop in the first half of the embryonic period and the less they develop after birth. On the contrary, in the development of the partial agglutinogens of $\mathrm{O}$ substance, i.e. $\mathrm{O}_{\mathrm{I}}, \mathrm{O}_{\mathrm{II}}$ and $\mathrm{O}_{\mathrm{III}}$, there is no remarkable difference to be observed among them, they all develop comparatively speedily in the first half of the embryonic period and even thereafter gradually develop all in the same way.

\section{References.}

1) M. Imamura : Hanzaigaku Zassi, 9(5):580-590, 1935.

2) K. Yamaguchi : Tckyo Igakkai Zasshi, 57(3):147-188, 1943.

3) C. Kobayashi : Tokyo Igakkai Zasshi, 56(11) : 382-456, 1942.

4) Y. Inou?: Tckyo Igakkai Zasshi, 57(E) : 1-55, 1942. 